Author affiliations and support information (if applicable) appear at the end of this article.

Published at jco.org on January 17, 2018.

K.A and R.A.K. are Expert Panel co-chairs. Clinical Practice Guideline Committee Approval: September 11, 2017

Editor's note: This American Society of Clinical Oncology (ASCO) Clinical Practice Guideline provides recommendations, with comprehensive review and analyses of the relevant literature for each recommendation. Additional information, including an abbreviated Data Supplement with new studies, a Methodology Supplement, slide sets, clinical tools and resources, and links to patient information at www.cancer.net, is available at www.asco.org/hematologicmalignancies-guidelines and www.asco. org/guidelineswiki.

Corresponding author: American Society of Clinical Oncology, 2318 Mill Rd, Suite 800, Alexandria, VA 22314; e-mail: guidelines@asco.org

(ㄷ 2018 by American Society of Clinical Oncology

0732-183X/18/3608w-812w/\$20.00

\title{
Role of Bone-Modifying Agents in Multiple Myeloma: American Society of Clinical Oncology Clinical Practice Guideline Update
}

Kenneth Anderson, Nofisat Ismaila, Patrick J. Flynn, Susan Halabi, Sundar Jagannath, Mohammed S. Ogaily, Jim Omel, Noopur Raje, G. David Roodman, Gary C. Yee, and Robert A. Kyle

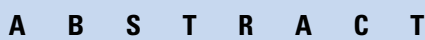

\section{Purpose}

To update guideline recommendations on the role of bone-modifying agents in multiple myeloma.

\section{Methods}

An update panel conducted a targeted systematic literature review by searching PubMed and the Cochrane Library for randomized controlled trials, systematic reviews, meta-analyses, clinical practice guidelines, and observational studies.

\section{Results}

Thirty-five relevant studies were identified, and updated evidence supports the current recommendations.

\section{Recommendations}

For patients with active symptomatic multiple myeloma that requires systemic therapy with or without evidence of lytic destruction of bone or compression fracture of the spine from osteopenia on plain radiograph(s) or other imaging studies, intravenous administration of pamidronate $90 \mathrm{mg}$ over at least 2 hours or zoledronic acid $4 \mathrm{mg}$ over at least 15 minutes every 3 to 4 weeks is recommended. Denosumab has shown to be noninferior to zoledronic acid for the prevention of skeletal-related events and provides an alternative. Fewer adverse events related to renal toxicity have been noted with denosumab compared with zoledronic acid and may be preferred in this setting. The update panel recommends that clinicians consider reducing the initial pamidronate dose in patients with preexisting renal impairment. Zoledronic acid has not been studied in patients with severe renal impairment and is not recommended in this setting. The update panel suggests that bone-modifying treatment continue for up to 2 years. Less frequent dosing has been evaluated and should be considered in patients with responsive or stable disease. Continuous use is at the discretion of the treating physician and the risk of ongoing skeletal morbidity. Retreatment should be initiated at the time of disease relapse. The update panel discusses measures regarding osteonecrosis of the jaw. Additional information is available at www.asco.org/hematologic-malignanciesguidelines and www.asco.org/guidelineswiki.

\section{J Clin Oncol 36:812-818. (C) 2018 by American Society of Clinical Oncology}

\section{INTRODUCTION}

The goal of this update is to provide oncologists, hematologists, other health care practitioners, patients, and caregivers with recommendations regarding the role of bone-modifying agents in multiple myeloma.

ASCO first published evidence-based clinical practice guidelines on the role of bisphosphonates in multiple myeloma in 2002 and an update in $2007 .{ }^{1}$ The goal of this 2017 guideline update is to provide oncologists and other clinicians with current recommendations regarding the role of bonemodifying agents (BMAs) in multiple myeloma. The current 2017 update assesses whether the 2007 recommendations remain valid. A complete list of previous recommendations is available at www.asco. org/hematologic-malignancies-guidelines.

\section{METHODS}

\section{Guideline Update Process}

ASCO uses a signals ${ }^{2}$ approach to facilitate guideline updating. This approach is intended to 


\section{Role of Bone-Modifying Agents in Multiple Myeloma: American Society of Clinical Oncology Clinical Practice Guideline Update}

\section{Guideline Question}

What is the role of BMAs in patients with multiple myeloma?

\section{Target Population}

Patients with multiple myeloma.

\section{Target Audience}

Medical oncologists, hematologists, radiation oncologists, oncology pharmacists, advanced practice providers, nurses, and other health care providers.

\section{Methods}

A systematic review of the literature was performed, and relevant evidence was evaluated for inclusion in this updated clinical practice guideline using the signals approach.

\section{Key Recommendations}

\section{Indications to initiate a BMA}

Patients with lytic disease on plain radiographs or other imaging studies. For patients with multiple myeloma who, on plain radiograph(s) or other imaging studies (magnetic resonance imaging or computed tomography Scan), have lytic destruction of the bone or compression fracture of the spine from osteopenia, intravenous pamidronate $90 \mathrm{mg}$ delivered over at least 2 hours or zoledronic acid $4 \mathrm{mg}$ delivered over at least 15 minutes every 3 to 4 weeks is recommended. Alternative treatment includes the use of denosumab, a monoclonal antibody that targets receptor activator of nuclear factor kappa-B ligand.

Patients with osteopenia in the absence of lytic disease. Starting bisphosphonates in patients with solitary plasmacytoma or smoldering (asymptomatic) or indolent myeloma is not recommended.

Adjunct to pain control in patients with pain as a result of osteolytic disease and those receiving other interventions for fractures or impending fractures. Intravenous pamidronate or zoledronic acid is recommended for patients with pain as a result of osteolytic disease and as an adjunctive treatment of patients receiving radiation therapy, analgesics, or surgical intervention to stabilize fractures or impending fractures. Denosumab is an additional option.

Patients with myeloma with normal plain radiograph or osteopenia in bone mineral density measurements. The Expert Panel supports starting intravenous bisphosphonates in patients with multiple myeloma with osteopenia (osteoporosis), but no radiographic evidence of lytic bone disease.

Patients with monoclonal gammopathy of undetermined significance. Starting bisphosphonates in patients with monoclonal gammopathy of undetermined significance is not recommended, unless osteopenia (osteoporosis) exists.

Dosing and selection of BMAs. As a result of increased concerns over renal adverse events, dosing guidelines for patients with preexisting renal impairment were added to the zoledronic acid package insert. Guidelines recommend that patients with preexisting mild-to-moderate renal impairment—estimated creatinine clearance, 30 to $60 \mathrm{~mL} / \mathrm{min}$ - should receive a reduced dosage of zoledronic acid. No changes in infusion time or interval are required. Zoledronic acid has not been studied in patients with severe renal impairment and is not recommended for use in these patients. Recent data that compare denosumab with zoledronic acid has demonstrated fewer adverse events related to renal toxicity with denosumab, and this may be preferred in patients with compromised renal function.

Pamidronate $90 \mathrm{mg}$ administered over 4 to 6 hours is recommended for patients with extensive bone disease and existing severe renal impairment—serum creatinine level $>3.0 \mathrm{mg} / \mathrm{dL}(265 \mu \mathrm{mol} / \mathrm{L})$ or an estimated creatinine clearance of $<30 \mathrm{~mL} / \mathrm{min}$. Although no dosing guidelines are available for patients with preexisting renal impairment, the Expert Panel recommends that clinicians consider reducing the initial pamidronate dose in that setting. Infusion times $<2$ hours with pamidronate or $<15$ minutes with zoledronic acid should be avoided.

(continued on following page) 
Duration of therapy. The Expert Panel suggests that bone-targeting treatment continue for a period of up to 2 years. Less-frequent dosing has been evaluated and should be considered in patients with responsive or stable disease. In patients who do not have active myeloma and are on maintenance therapy, the physician may consider a 3-month interval of bisphosphonate administration. There are no data to support a more precise recommendation for the duration of bisphosphonate therapy in this group of patients. For those patients for whom bisphosphonates were withdrawn after 2 years, the drug should be resumed upon relapse with new-onset skeletalrelated events. Denosumab should not be stopped abruptly, given its reversible mechanism of action.

Monitoring. The Expert Panel recommends that serum creatinine should be monitored before each dose of pamidronate or zoledronic acid, in accordance with US Food and Drug Administration (FDA)-approved labeling. Denosumab does not require monitoring of renal function.

In patients who develop renal deterioration without an apparent cause during bisphosphonate therapy, zoledronic acid or pamidronate should be withheld. Bisphosphonate therapy can be resumed at the same dosage as that before treatment interruption, when serum creatinine returns to within $10 \%$ of the baseline level. Denosumab requires no dose modification.

Serum calcium should be monitored regularly, and serum vitamin D levels should be evaluated intermittently. Hypocalcemia is an adverse effect of all bone resorptive agents and is more pronounced with denosumab. Patients should be calcium and vitamin $\mathrm{D}$ repleted.

The Expert Panel also recommends intermittent evaluation-every 3 to 6 months-of all patients receiving pamidronate or zoledronic acid therapy for the presence of albuminuria on a spot urine sample. In patients who experience unexplained albuminuria, a 24-hour urine collection should be obtained to assess for $>500 \mathrm{mg} / 24$ hours of urinary albumin, and discontinuation of the drug is advised until renal problems are resolved. These patients should be reassessed every 3 to 4 weeks-with a 24-hour urine collection for total protein and urine protein electrophoresis — and pamidronate should be reinstituted over a longer infusion time ( $\geq 4$ hours) and at doses not to exceed $90 \mathrm{mg}$ every 4 weeks when renal function returns to baseline.

The Expert Panel supports the use of screening urinalysis for proteinuria, but underscores that a 24-hour urine collection for the determination of total protein and electrophoresis is required if the test is positive. Although no similar guidelines are available for zoledronic acid, some Expert Panel members recommend that zoledronic acid be reinstituted over a longer infusion time ( $\geq 30$ minutes).

Biochemical markers. Use of the biochemical markers of bone metabolism to monitor bone-modifying therapy use is not suggested for routine care.

Osteonecrosis of the jaw. Osteonecrosis of the jaw $(\mathrm{ONJ})$ is an uncommon but potentially serious complication of intravenous bisphosphonates and denosumab. The Expert Panel agrees with the recommendations described in the revised FDA label for zoledronic acid and pamidronate, Dear Doctor letters, a white paper, and various position papers or statements. All patients should receive a comprehensive dental examination and appropriate preventive dentistry before bone-modifying therapy. Active oral infections should be treated, and sites that are at high risk for infection should be eliminated. While on therapy, patients should maintain excellent oral hygiene and avoid invasive dental procedures, if possible. Continuation of a bone-targeting agent in the setting of ONJ has to be individualized and dependent on a risk-benefit ratio and the severity of bone disease.

\section{Additional resources}

More information, including a Data Supplement with additional evidence tables, a Methodology Supplement with information about evidence quality and strength of recommendations, slide sets, and clinical tools and resources, is available at www.asco.org/ hematologic-malignancies-guidelines and www.asco.org/guidelineswiki. Patient information is available at www.cancer.net.

\section{ASCO believes that cancer clinical trials are vital to inform medical decisions and improve cancer care, and that all patients should} have the opportunity to participate.

identify new, potentially practice-changing data-signals—-that might translate into revised practice recommendations. The approach relies on routine searches of the literature and the expertise of ASCO guideline panel members to identify signals. The Methodology Supplement, available at www.asco.org/hematologic-malignancies-guidelines, provides additional information about the signals approach.

PubMed and the Cochrane Library were searched for randomized controlled trials, systematic reviews, meta-analyses, clinical practice guidelines, and observational studies for the period from January 2007 through July 2017. The disease and intervention search terms used were those that were used for the 2007 guideline. An Expert Panel-members listed in Appendix Table A1, (online only)—was formed in accordance with the ASCO Conflict of Interest Management Procedures for Clinical Practice Guidelines, and the panel reviewed the abstracts that were identified on the basis of predefined signals that would suggest the need to change a previous recommendation. Additional information about the results of the updated literature search (Data Supplement 1) and the 2017 search strategy string and results (Data Supplement 2), as well as 
a discussion of the ASCO signals approach to guideline updating, are available at www.asco.org/hematologic-malignancies-guidelines and in the 2017 Data Supplement and 2017 Methodology Supplement, respectively. A QUOROM diagram of the updated search and the clinical questions are provided in Data Supplements 3 and 4, respectively.

This systematic review-based guideline product was developed by an Expert Panel with multidisciplinary representation, including patients, and by ASCO guidelines staff with health research methodology experience. The Expert Panel met via teleconference calls to consider the evidence for each of the 2017 recommendations. The guideline was circulated in draft form to the Expert Panel. ASCO's Clinical Practice Guidelines Committee leadership reviewed and approved the final document. All funding for the administration of the project was provided by ASCO.

Guideline Disclaimer. The Clinical Practice Guidelines and other guidance published herein are provided by ASCO to assist providers in clinical decision making. The information herein should not be relied upon as being complete or accurate, nor should it be considered as inclusive of all proper treatments or methods of care or as a statement of the standard of care. With the rapid development of scientific knowledge, new evidence may emerge between the time information is developed and when it is published or read. The information is not continually updated and may not reflect the most recent evidence. The information addresses only the topics specifically identified therein and is not applicable to other interventions, diseases, or stages of diseases. This information does not mandate any particular course of medical care. Furthermore, the information is not intended to substitute for the independent professional judgment of the treating provider, as the information does not account for individual variation among patients. Recommendations reflect high, moderate, or low confidence that the recommendation reflects the net effect of a given course of action. The use of words like "must," "must not," "should," and "should not" indicates that a course of action is recommended or not recommended for either most or many patients, but there is latitude for the treating physician to select other courses of action in individual cases. In all cases, the selected course of action should be considered by the treating provider in the context of treating the individual patient. Use of the information is voluntary. ASCO provides this information on an "as is" basis and makes no warranty, express or implied, regarding the information. ASCO specifically disclaims any warranties of merchantability or fitness for a particular use or purpose. ASCO assumes no responsibility for any injury or damage to persons or property arising out of or related to any use of this information, or for any errors or omissions.

This is the most recent information as of the publication date. For the most recent information, and to submit new evidence, please visit www. asco.org/hematologic-malignancies-guidelines and the ASCO Guidelines Wiki (www.asco.org/guidelineswiki).

Guideline and Conflicts of Interest. The Expert Panel was assembled in accordance with ASCO's Conflict of Interest Policy Implementation for Clinical Practice Guidelines ("Policy," found at http://www.asco.org/rwc). All members of the Expert Panel completed ASCO’s disclosure form, which requires disclosure of financial and other interests, including relationships with commercial entities that are reasonably likely to experience direct regulatory or commercial impact as a result of promulgation of the guideline. Categories for disclosure include employment; leadership; stock or other ownership; honoraria, consulting or advisory role; speaker's bureau; research funding; patents, royalties, other intellectual property; expert testimony; travel, accommodations, expenses; and other relationships. In accordance with the Policy, the majority of the members of the Expert Panel did not disclose any relationships constituting a conflict under the Policy.

\section{RESULTS}

The search yielded 35 publications. ${ }^{3-37}$ After careful review of the identified publications, the Expert Panel concluded that additional BMAs are now available, and the 2007 guideline recommendations ${ }^{1}$ have been updated. The guideline recommendations also provide information to additionally clarify the evidence that supports additional recommendations on duration and complications of BMAs. A bibliography and summary of the results of the updated literature search is provided in Data Supplement 2.

\section{RECOMMENDATIONS}

The 2017 recommendations are listed in the Bottom Line Box. These recommendations are consistent with the previous recommendations, with new information on denosumab, a receptor activator of nuclear factor kappa-B ligand inhibitor. ${ }^{36}$ Additional modifications were made to some of the recommendations on the basis of recent data to better clarify the indications for treatment, duration of treatment, and associated complications of treatment, and these are discussed in greater depth in this section.

The definition of active multiple myeloma that requires therapy has been revised. Hypercalcemia, renal dysfunction, anemia, or bone disease remain indications for treatment. In the absence of these features, patients who have $>60 \%$ bone marrow plasma cells, involved free light chain $>100 \mathrm{mg} / \mathrm{L}$ with $\kappa / \lambda$ ratio $>100$-fold, or more than one site of bone disease on magnetic resonance imaging or on positron emission tomography computed tomography scanning are now recommended for treatment. Any patient who receives treatment for active multiple myeloma should receive bisphosphonate therapy. In a large randomized trial that was conducted in the United Kingdom (MRC IX Trial), patients without lytic bone disease also benefitted from bisphosphonate therapy (zoledronic acid) with reduced skeletalrelated events at the time of relapse, and there was improvement in progression-free survival, but not overall survival. ${ }^{20,21}$ Clodronate is approved worldwide, except in the United States, for either oral or intravenous administration; however, the recent MRC IX randomized controlled trial demonstrates that intravenous zoledronic acid is superior for avoiding skeletal complications. ${ }^{20,21}$

\section{Patients With Lytic Disease on Plain Radiographs or Other Imaging Studies}

The previous guidelines recommended the use of intravenous bisphosphonates for patients with myeloma with evidence of bone disease. ${ }^{1}$ Denosumab was studied in a large, international, randomized, double-blinded, phase III study that evaluated the efficacy and safety of denosumab compared with zoledronic acid for the prevention of skeletal-related events in patients with newly diagnosed multiple myeloma. ${ }^{36,37}$ Patients $(\mathrm{N}=1,718)$ were randomly assigned in a 1:1 allocation ratio to denosumab $120 \mathrm{mg}$ subcutaneously every 4 weeks or zoledronic acid $4 \mathrm{mg}$ intravenously every 4 weeks. Denosumab was noninferior to zoledronic acid in delaying the time to first skeletal-related events. Overall survival for patients who were treated with denosumab was not different than patients who were treated with zoledronic acid. Fewer adverse events related to renal toxicity were reported with denosumab, providing an additional option as a BMA in multiple myeloma.

Denosumab is more expensive than zoledronic acid or pamidronate and must be considered in treatment decisions. Table 1 provides an overview of the estimated cost of these medications in the United States. 
Table 1. Estimated Prices for Bone-Modifying Agents in the United States

\begin{tabular}{|c|c|c|c|c|}
\hline Agent (route) & Dose (mg) & Schedule & $\begin{array}{l}\text { Price Per Dose } \\
\text { (US dollars) }\end{array}$ & $\begin{array}{c}\text { Total Price Per 1-Year Treatment Cycle } \\
\text { (US dollars) }\end{array}$ \\
\hline \multicolumn{5}{|l|}{ Bisphosphonate } \\
\hline $\begin{array}{l}\text { Pamidronate } \\
\quad \text { (intravenous) }\end{array}$ & 90 & $\begin{array}{l}\text { Delivered over no less than } 2 \text { hours every } \\
3 \text { or } 4 \text { weeks }\end{array}$ & $\$ 30.67^{*}$ & Every-4-weeks price: $\$ 398.71(\$ 30.67 \times 13)$ \\
\hline \multirow[t]{2}{*}{$\begin{array}{l}\text { Zoledronic acid } \\
\text { (intravenous) }\end{array}$} & 4 & $\begin{array}{l}\text { Delivered over no less than } 15 \text { minutes } \\
\text { every } 12 \text { weeks or every } 3-4 \text { weeks }\end{array}$ & $\$ 53.64 \dagger$ & Every-12-weeks price: $\$ 214.56(\$ 53.64 \times 4)$ \\
\hline & & & & Every-4-weeks price: $\$ 697.37$ (\$53.64 × 13) \\
\hline \multicolumn{5}{|l|}{ Monoclonal antibody } \\
\hline $\begin{array}{l}\text { Denosumab } \\
\text { (subcutaneous } \\
\text { injection) }\end{array}$ & 120 & Every 4 weeks & $\$ 1,995.48 \ddagger$ & Every-4-weeks price: $\$ 25,941.24(\$ 1,995.48 \times 13)$ \\
\hline \multicolumn{5}{|c|}{$\begin{array}{l}\text { NOTE. Prices per dose were for a single infusion or per single injection. Prices for drugs reimbursed through Medicare Part B only were identified from the second } \\
\text { quarter } 2017 \text { Medicare Payment Allowable Part B Drugs Average Sales Price data. }{ }^{39} \text { Drug price may vary by plan and by pharmacy where a medication is filled (eg, } \\
\text { preferred or nonpreferred pharmacies). Drug prices are dynamic, and thus the prices listed in the table may not reflect current prices. Bone-modifying treatment continue } \\
\text { for a period of up to } 2 \text { years. Less-frequent dosing has been evaluated and should be considered in patients with responsive or stable disease. Continuous use is at the } \\
\text { discretion of the treating physician and the risk of ongoing skeletal morbidity. Retreatment should be initiated at the time of disease relapse. While on therapy, patients } \\
\text { should maintain excellent oral hygiene and avoid invasive dental procedures. } \\
* \$ 10.223 / 30 \mathrm{mg} \times 3 \text {. } \\
+\$ 13.411 / 1 \mathrm{mg} \times 4 \text {. } \\
\neq \$ 16.629 / 1 \mathrm{mg} \times 120 .\end{array}$} \\
\hline
\end{tabular}

\section{Duration and Frequency of Therapy}

The risk of ONJ has prompted the use of less-frequent dosing of zoledronic acid, which may be an option for patients. ${ }^{26,38}$ These two studies were carried out to address the dosing of zoledronic acid every 3 months. To this end, the Z-MARK study evaluated whether patients with 1 to 2 years of prior intravenous bisphosphonate therapy could be treated safely long term with less-frequent zoledronic acid on the basis of markers of bone turnover. ${ }^{26}$ Patients with urinary N-telopeptide of type I collagen (uNTX) levels $<50 \mathrm{nmol} / \mathrm{mmol}$ creatinine received zoledronate $4 \mathrm{mg}$ every 12 weeks versus every 4 weeks for higher levels of uNTX. uNTX levels were monitored over the course of treatment, and the dosing of zoledronic acid was adjusted as a result. In addition, patients who developed a skeletal-related event or who experienced disease progression were treated on the every-4-week schedule thereafter, regardless of uNTX levels. The majority of patients (79 of 121) received the every-12-week schedule throughout the study. Of the 79 patients, only seven patients $(8.9 \%)$ had a skeletal-related event in year 1 and five in year 2 . The low incidence of skeletal-related events overall in this study compared with prior studies with zoledronic acid suggests that less-frequent dosing of zoledronic acid beyond 1 to 2 years may continue to reduce the risk of skeletal-related events. Furthermore, it also suggests more effective treatment of multiple myeloma with novel therapies may have protective effects on the bone.

In another large randomized trial, zoledronic acid that was administered every 12 weeks was compared with that administered every 4 weeks to demonstrate noninferiority. ${ }^{38}$ This randomized, open-label clinical trial included 1,822 patients with at least one site of bone involvement for a treatment duration of 2 years. Two hundred seventy-two patients in this trial had multiple myeloma. The proportions of skeletal-related events did not differ significantly between the every-4-week dosing group versus the every-12-week dosing group. Among other end points, there was no difference noted in the incidence of ONJ and kidney dysfunction. At the time of relapse, retreatment on the 4-week schedule is recommended.

Although both these studies have used less-frequent dosing, there are several limitations that should be kept in mind. The
Z-MARK study was a single-arm study with only 121 patients included; however, this trial did address patients who received up to 4 years of bisphosphonate treatment. In contrast, the trial by Himmelstein et al was randomized, but only included 272 patients with myeloma. Moreover, in this open-label trial, nearly $40 \%$ of patients did not complete the stipulated 2-year duration of the study. Finally, this trial did not address the duration of therapy beyond 2 years. Given these caveats, the guidelines committee has only made these as suggested recommendations.

\section{ONJ}

$\mathrm{ONJ}$ is a major complication that is increasingly observed when more potent bisphosphonates, such as pamidronate and zoledronic acid, have been used. Although first described with bisphosphonates, ONJ also occurs with denosumab. The Expert Panel agrees with the recommendations described in the revised FDA label for zoledronic acid and pamidronate, Dear Doctor letters, a white paper, and various position papers or statements. All patients with cancer should receive a comprehensive dental examination and appropriate preventive dentistry before bone-modifying therapy. Active oral infections should be treated, and sites that are at high risk for infection should be eliminated. While on therapy, patients should maintain excellent oral hygiene and avoid invasive dental procedures, if possible. Continuation of a bone-targeting agent in the setting of ONJ has to be individualized and dependent on a risk-benefit ratio and the severity of bone disease. Other notable complications of BMAs include atypical fractures of the femur. ${ }^{19}$

ASCO believes that cancer clinical trials are vital to inform medical decisions and improve cancer care, and that all patients should have the opportunity to participate.

\section{ADDITIONAL RESOURCES}

More information, including Data and Methodology Supplements, slide sets, and clinical tools and resources, is available at www.asco. 
org/hematologic-malignancies-guidelines. Patient information is available at www.cancer.net. Visit www.asco.org/guidelineswiki to provide comments on the guideline or to submit new evidence.

\section{Related ASCO Guidelines}

- Role of Bisphosphonates in Multiple Myeloma ${ }^{1}$ (http:// ascopubs.org/doi/10.1200/jco.2007.12.1269)

- Management of Chronic Pain in Survivors of Adult Cancers $^{40}$ (http://ascopubs.org/doi/10.1200/JCO.2016. 68.5206)

- Screening, Assessment, and Management of Fatigue in Adult Survivors of Cancer Guideline Adaptation ${ }^{41}$ (http://ascopubs.org/doi/10.1200/jco.2013.53.4495)

- Integration of Palliative Care into Standard Oncology Practice $^{42}$ (http://ascopubs.org/doi/10.1200/JCO.2016. 70.1474)

- Patient-Clinician Communication ${ }^{43}$ (http://ascopubs. org/doi/10.1200/JCO.2017.75.2311)

\section{AUTHORS' DISCLOSURES OF POTENTIAL CONFLICTS} OF INTEREST

Disclosures provided by the authors are available with this article at jco.org.

\section{AUTHOR CONTRIBUTIONS}

Manuscript writing: All authors

Final approval of manuscript: All authors

Accountable for all aspects of the work: All authors

\section{REFERENCES}

1. Kyle RA, Yee GC, Somerfield MR, et al: American Society of Clinical Oncology 2007 clinical practice guideline update on the role of bisphosphonates in multiple myeloma. J Clin Oncol 25:2464-2472, 2007

2. Shojania KG, Sampson $M$, Ansari $M T$, et al: How quickly do systematic reviews go out of date? A survival analysis. Ann Intern Med 147:224-233, 2007

3. D'Arena G, Gobbi PG, Broglia C, et al: Pamidronate versus observation in asymptomatic myeloma: Final results with long-term follow-up of a randomized study. Leuk Lymphoma 52:771-775, 2011

4. Badros A, Terpos E, Katodritou E, et al: Natural history of osteonecrosis of the jaw in patients with multiple myeloma. J Clin Oncol 26:5904-5909, 2008

5. Berenson JR, Yellin O, Boccia RV, et al: Zoledronic acid markedly improves bone mineral density for patients with monoclonal gammopathy of undetermined significance and bone loss. Clin Cancer Res 14:6289-6295, 2008

6. Berenson JR, Yellin O, Crowley J, et al: Prognostic factors and jaw and renal complications among multiple myeloma patients treated with zoledronic acid. Am J Hematol 86:25-30, 2011

7. Delforge $M$, Terpos $E$, Richardson $P G$, et al: Fewer bone disease events, improvement in bone remodeling, and evidence of bone healing with bortezomib plus melphalan-prednisone vs. melphalanprednisone in the phase III VISTA trial in multiple myeloma. Eur J Haematol 86:372-384, 2011

8. Dimopoulos MA, Kastritis E, Bamia C, et al: Reduction of osteonecrosis of the jaw (ONJ) after implementation of preventive measures in patients with multiple myeloma treated with zoledronic acid. Ann Oncol 20:117-120, 2009

9. Gabbert TI, Hoffmeister B, Felsenberg D: Risk factors influencing the duration of treatment with bisphosphonates until occurrence of an osteonecrosis of the jaw in 963 cancer patients. J Cancer Res Clin Oncol 141:749-758, 2015

10. García-Sanz R, Oriol A, Moreno MJ, et al: Zoledronic acid as compared with observation in multiple myeloma patients at biochemical relapse: Results of the randomized AZABACHE Spanish trial. Haematologica 100:1207-1213, 2015

11. Geng CJ, Liang $\mathrm{Q}$, Zhong JH, et al: Ibandronate to treat skeletal-related events and bone pain in metastatic bone disease or multiple myeloma: A meta-analysis of randomised clinical trials. BMJ Open 5:e007258, 2015

12. Gimsing $P$, Carlson $K$, Turesson I, et al: Effect of pamidronate $30 \mathrm{mg}$ versus $90 \mathrm{mg}$ on physical function in patients with newly diagnosed multiple myeloma (Nordic Myeloma Study Group): A doubleblind, randomised controlled trial. Lancet Oncol 11: 973-982, 2010

13. Hageman $K$, Patel KC, Mace $K$, et al: The role of denosumab for prevention of skeletal-related complications in multiple myeloma. Ann Pharmacother 47:1069-1074, 2013

14. Henry DH, Costa L, Goldwasser F, et al: Randomized, double-blind study of denosumab versus zoledronic acid in the treatment of bone metastases in patients with advanced cancer (excluding breast and prostate cancer) or multiple myeloma. J Clin Oncol 29:1125-1132, 2011

15. Jackson GH, Morgan GJ, Davies FE, et al: Osteonecrosis of the jaw and renal safety in patients with newly diagnosed multiple myeloma: Medical Research Council Myeloma IX study results. Br J Haematol 166:109-117, 2014

16. Jung TI, Hoffmann F, Glaeske G, et al: Disease-specific risk for an osteonecrosis of the jaw under bisphosphonate therapy. J Cancer Res Clin Oncol 136:363-370, 2010

17. Kumar A, Galeb S, Djulbegovic B: Treatment of patients with multiple myeloma: An overview of systematic reviews. Acta Haematol 125:8-22, 2011
18. Laroche $M$, Lemaire $O$, Bourin $P$, et al: Dualenergy $X$-ray absorptiometry and biochemical markers of bone turnover after autologous stem cell transplantation in myeloma. Eur J Haematol 88:388-395, 2012

19. Mhaskar R, Redzepovic J, Wheatley K, et al: Bisphosphonates in multiple myeloma. Cochrane Database Syst Rev (3):CD003188, 2010

20. Morgan GJ, Davies FE, Gregory WM, et al: First-line treatment with zoledronic acid as compared with clodronic acid in multiple myeloma (MRC Myeloma (X): A randomised controlled trial. Lancet 376: 1989-1999, 2010

21. Morgan GJ, Davies FE, Gregory WM, et al: Effects of induction and maintenance plus longterm bisphosphonates on bone disease in patients with multiple myeloma: The Medical Research Council Myeloma IX Trial. Blood 119:5374-5383, 2012

22. Musto $P$, Petrucci $M T$, Bringhen $S$, et al: $A$ multicenter, randomized clinical trial comparing zoledronic acid versus observation in patients with asymptomatic myeloma. Cancer 113:1588-1595, 2008

23. Patel CG, Yee AJ, Scullen TA, et al: Biomarkers of bone remodeling in multiple myeloma patients to tailor bisphosphonate therapy. Clin Cancer Res 20:3955-3961, 2014

24. Peng F, Fu R, Liu $H$, et al: Clinical significance of serum bone metabolic markers in diagnosis and monitoring of myeloma bone disease [in Chinese]. Zhonghua Yi Xue Za Zhi 95:3436-3439, 2015

25. Raje N, Vadhan-Raj S, Willenbacher W, et al: Evaluating results from the multiple myeloma patient subset treated with denosumab or zoledronic acid in a randomized phase 3 trial. Blood Cancer J 6:e378, 2016

26. Raje $N$, Vescio R, Montgomery CW, et al: Bone marker-directed dosing of zoledronic acid for the prevention of skeletal complications in patients 
with multiple myeloma: Results of the Z-MARK study. Clin Cancer Res 22:1378-1384, 2016

27. Spencer A, Roberts $A$, Kennedy N, et al: Renal safety of zoledronic acid with thalidomide in patients with myeloma: A pharmacokinetic and safety substudy. BMC Clin Pharmacol 8:2, 2008

28. Tatekoshi $A$, Sato $T$, Ibata $S$, et al: Markers of bone metabolism in multiple myeloma patients switched from zoledronic acid to denosumab. Rinsho Ketsueki 55:2271-2276, 2014

29. Terpos E, Christoulas D, Kastritis E, et al: VTD consolidation, without bisphosphonates, reduces bone resorption and is associated with a very low incidence of skeletal-related events in myeloma patients post ASCT. Leukemia 28:928-934, 2014

30. Thumbigere-Math $\vee$, Tu L, Huckabay $S$, et al: A retrospective study evaluating frequency and risk factors of osteonecrosis of the jaw in 576 cancer patients receiving intravenous bisphosphonates. Am J Clin Oncol 35:386-392, 2012

31. Vahtsevanos $K$, Kyrgidis A, Verrou $E$, et al: Longitudinal cohort study of risk factors in cancer patients of bisphosphonate-related osteonecrosis of the jaw. J Clin Oncol 27:5356-5362, 2009

32. Van den Wyngaert $T$, Delforge M, Doyen $C$, et al: Prospective observational study of treatment pattern, effectiveness and safety of zoledronic acid therapy beyond 24 months in patients with multiple myeloma or bone metastases from solid tumors. Support Care Cancer 21:3483-3490, 2013

33. Varadarajan $\mathrm{P}$, Toro JJ, Lee $\mathrm{S}$, et al: Hematopoietic progenitor cell transplantation toxicities in multiple myeloma patients with bisphosphonate-induced osteonecrosis of the jaw: A longitudinal cohort study. Support Care Cancer 20:2969-2975, 2012

34. Vij R, Horvath N, Spencer A, et al: An openlabel, phase 2 trial of denosumab in the treatment of relapsed or plateau-phase multiple myeloma. Am J Hematol 84:650-656, 2009

35. Weide R, Koppler $H$, Antras L, et al: Rena toxicity in patients with multiple myeloma receiving zoledronic acid vs. ibandronate: A retrospective medical records review. J Cancer Res Ther 6:31-35, 2010

36. Raje NS, Roodman GD, Willenbacher W et al: Impact of denosumab (DMB) compared with zoledronic acid (ZA) on renal function in the treatment of myeloma bone disease. J Clin Oncol 35: 8005, 2017

37. Raje N, Terpos E, Willenbacher W, et al: An international, randomised, double-blind study of denosumab compared to zoledronic acid in bone disease treatment of newly diagnosed multiple myeloma. Lancet Oncol (in press)

38. Himelstein $A L$, Foster JC, Khatcheressian JL, et al: Effect of longer-interval vs standard dosing of zoledronic acid on skeletal events in patients with bone metastases: A randomized clinical trial. JAMA 317:48-58, 2017

39. Centers for Medicare \& Medicaid Services: Second quarter 2017 Medicare Payment Allowable Part B Drugs Average Sales Price data. https://www.cms.gov/ apps/ama/license.asp?file=/Medicare/Medicare-Feefor-Service-Part-B-Drugs/McrPartBDrugAvgSalesPrice/ Downloads/2017-April-ASP-Pricing.zip

40. Paice JA, Portenoy R, Lacchetti $C$, et al: Management of chronic pain in survivors of adult cancers: American Society of Clinical Oncology clinical practice guideline. J Clin Oncol 34:3325-3345, 2016

41. Bower JE, Bak K, Berger $A$, et al: Screening, assessment, and management of fatigue in adult survivors of cancer: An American Society of Clinical oncology clinical practice guideline adaptation. J Clin Oncol 32:1840-1850, 2014

42. Ferrell BR, Temel JS, Temin $\mathrm{S}$, et al: Integration of palliative care into standard oncology care: American Society of Clinical Oncology clinical practice guideline update. J Clin Oncol 35:96-112, 2017

43. Gilligan $T$, Coyle N, Frankel RM, et al: Patientclinician communication: American Society of Clinical Oncology consensus guideline. J Clin Oncol 35: 3618-3632, 2017

\section{Affiliations}

Kenneth Anderson, Dana-Farber Cancer Institute; Noopur Raje, Massachusetts General Hospital, Boston, MA; Nofisat Ismaila, American Society of Clinical Oncology, Alexandria, VA; Patrick J. Flynn, Minnesota Oncology, Woodbury; Robert A. Kyle, Mayo Clinic, Rochester, MN; Susan Halabi, Duke University Medical Center, Durham, NC; Sundar Jagannath, Mount Sinai Medical Center, New York, NY; Mohammed S. Ogaily, Beuamont Center for Hematology and Oncology-Downriver, Brownstown, MI; Jim Omel, Education and Advocacy, Grand Island; Gary C. Yee, University of Nebraska Medical Center, Omaha, NE; and G. David Roodman, Indiana University School of Medicine, Indianapolis, IN. 


\section{AUTHORS' DISCLOSURES OF POTENTIAL CONFLICTS OF INTEREST}

Role of Bone-Modifying Agents in Multiple Myeloma: American Society of Clinical Oncology Clinical Practice Guideline Update

The following represents disclosure information provided by authors of this manuscript. All relationships are considered compensated. Relationships are self-held unless noted. I = Immediate Family Member, Inst = My Institution. Relationships may not relate to the subject matter of this manuscript. For more information about ASCO's conflict of interest policy, please refer to www.asco.org/rwc or ascopubs.org/jco/site/ifc.

\section{Kenneth Anderson}

Consulting or Advisory Role: Celgene, Millennium Pharmaceuticals, Gilead Sciences, Bristol-Myers Squibb

Patents, Royalties, Other Intellectual Property: C4 Therapeutics, OncoPep

\section{Nofisat Ismaila}

No relationship to disclose

Patrick J. Flynn

Employment: ARIAD Pharmaceuticals (I), Sanofi (I), Genzyme (I) Stock or Other Ownership: ARIAD Pharmaceuticals (I), Sanofi (I), Genzyme (I)

Consulting or Advisory Role: Shire

Speakers' Bureau: Eli Lilly

\section{Susan Halabi}

No relationship to disclose

Sundar Jagannath

Honoraria: Celgene, Bristol-Myers Squibb, Novartis, Janssen Pharmaceuticals, Merck

Consulting or Advisory Role: Celgene, Bristol-Myers Squibb, Janssen Pharmaceuticals, Novartis, Merck

\section{Mohammed S. Ogaily}

Honoraria: Novartis

Consulting or Advisory Role: Pfizer, BioTheranostics

Jim Omel

Honoraria: Takeda

Travel, Accommodations, Expenses: Takeda

Noopur Raje

Consulting or Advisory Role: Amgen, Celgene, Takeda, Novartis Research Funding: AstraZeneca (Inst)

G. David Roodman

Consulting or Advisory Role: Amgen

Gary C. Yee

Honoraria: Pharmacy Times

Travel, Accommodations, Expenses: Pharmacy Times

Robert A. Kyle

Consulting or Advisory Role: Celgene, Bristol-Myers Squibb, Pharmacyclics, Pfizer 


\section{Acknowledgment}

The Expert Panel wishes to thank Joseph Mikhael, MD, Sarbajit Mukherjee, MD, and the Clinical Practice Guidelines Committee for thoughtful reviews and insightful comments on this guideline.

\section{Appendix}

\begin{tabular}{|c|c|c|}
\hline Name (designation) & Affiliation/Institution & Role/Area of Expertise \\
\hline Kenneth Anderson, MD (co-chair) & Dana-Farber Cancer Institute, Boston, MA & Medical oncology \\
\hline Robert A. Kyle, MD (co-chair) & Mayo Clinic, Rochester, MN & Hematology/oncology \\
\hline Patrick J. Flynn, MD & Minnesota Oncology, Woodbury, MN & Hematology/oncology \\
\hline Sundar Jagannath, MD & Mount Sinai Medical Center, New York, NY & Medical oncology \\
\hline Susan Halabi, PhD & Duke University Medical Center, Durham, NC & Biostatistics/epidemiology \\
\hline Noopur Raje, MD & Massachusetts General Hospital, Boston, MA & Hematology/oncology \\
\hline David Roodman, MD, PhD & Indiana University School of Medicine, Indianapolis, IN & Hematology/oncology \\
\hline Gary C. Yee, PharmD & University of Nebraska Medical Center, Omaha, NE & Pharmacology \\
\hline Jim Omel, MD & Education and Advocacy, Grand Island, NE & Patient representative \\
\hline Mohammed S. Ogaily, MD & $\begin{array}{l}\text { Beaumont Center for Hematology and Oncology-Downriver } \\
\text { Brownstown, MI }\end{array}$ & $\begin{array}{l}\text { Practice Guidelines Implementation Network } \\
\text { representative }\end{array}$ \\
\hline Nofisat Ismaila, MD & American Society of Clinical Oncology, Alexandria, VA & Staff/health research methodologist \\
\hline
\end{tabular}

